\title{
IL-7 is a potent and proviral strain-specific inducer of latent HIV-1 cellular reservoirs of infected individuals on virally suppressive HAART
}

\author{
Feng-Xiang Wang, ${ }^{1}$ Yan Xu, ${ }^{1}$ Julie Sullivan, ${ }^{1}$ Emily Souder, ${ }^{1}$ Elias G. Argyris, ${ }^{1}$ \\ Edward A. Acheampong, ${ }^{1}$ Jaime Fisher, ${ }^{1}$ Maria Sierra, ${ }^{2}$ Michael M. Thomson, ${ }^{2}$ \\ Rafael Najera, ${ }^{2}$ lan Frank, ${ }^{3}$ Joseph Kulkosky, ${ }^{1}$ Roger J. Pomerantz, ${ }^{1}$ and Giuseppe Nunnari1 \\ ${ }^{1}$ Center for Human Virology and Biodefense, Division of Infectious Diseases and Environmental Medicine, Department of Medicine, \\ Thomas Jefferson University, Philadelphia, Pennsylvania, USA. ${ }^{2}$ Area de Patogenia Viral, Centro Nacional de Microbiologia, Instituto de Salud Carlos III, \\ Madrid, Spain. ${ }^{3}$ University of Pennsylvania, Division of Infectious Diseases, Philadelphia, Pennsylvania, USA.
}

\begin{abstract}
The persistence of HIV-1 in virally suppressed infected individuals on highly active antiretroviral therapy (HAART) remains a major therapeutic problem. The use of cytokines has been envisioned as an additional therapeutic strategy to stimulate latent proviruses in these individuals. Immune activation therapy using IL-2 has shown some promise. In the present study, we found that IL-7 was significantly more effective at enhancing HIV-1 proviral reactivation than either IL-2 alone or IL-2 combined with phytohemagglutinin (PHA) in CD8-depleted PBMCs. IL-7 also showed a positive trend for inducing proviral reactivation from resting CD4 ${ }^{+}$ T lymphocytes from HIV-1-infected patients on suppressive HAART. Moreover, the phylogenetic analyses of viral envelope gp120 genes from induced viruses indicated that distinct proviral quasispecies had been activated by IL-7, as compared with those activated by the PHA/IL-2 treatment. These studies thus demonstrate that different activators of proviral latency may perturb and potentially deplete only selected, specific portions of the proviral archive in virally suppressed individuals. The known immunomodulatory effects of IL-7 could be combined with its ability to stimulate HIV-1 replication from resting CD4 ${ }^{+} \mathrm{T}$ lymphocytes, in addition to other moieties, to potentially deplete HIV-1 reservoirs and lead to the rational design of immuneantiretroviral approaches.
\end{abstract}

\section{Introduction}

Highly active antiretroviral therapy (HAART) has dramatically altered the HIV-1 pandemic, at least in the developed world. Most patients treated with HAART maintain clinically undetectable plasma viral loads with concomitant dramatic decreases in mortality and morbidity. However, persistently infected resting CD4 ${ }^{+} \mathrm{T}$ lymphocytes have been demonstrated in the peripheral blood of HIV-1infected individuals even after treatment effectively suppressed most productive viral infection (1). It has been estimated that most HIV-1infected individuals would require complete suppression of viral replication for many decades on current HAART regimens to possibly reach viral eradication (1). Therefore, new treatment strategies designed to purge the pool of latently infected cells are required.

Cytokine treatment has been proposed not only as an immuneadjunctive therapy to HAART, but also to activate latently infected $\mathrm{CD}^{+} \mathrm{T}$ lymphocytes and increase the turnover rate of the latent viral reservoir to promote viral clearance. Several cytokines, including IL-2, IL-7, and IL-15, which share a common $\gamma$ chain, might have putative roles in improving control of HIV-1 infection; of these, IL-2 is the best characterized (2-4). Although recombinant human IL-2 (rhIL-2) plus HAART produced signifi-

Nonstandard abbreviations used: HAART, highly active antiretroviral therapy; LTR long terminal repeat; PHA, phytohemagglutinin; rhIL-2, recombinant human IL-2. Conflict of interest: The authors have declared that no conflict of interest exists.

Citation for this article: J. Clin. Invest. 115:128-137 (2005).

doi:10.1172/JCI200522574. cant $\mathrm{CD}^{+} \mathrm{T}$ lymphocyte expansion without an increase in viral load (5-8), the effects of this combination on purging viral reservoirs is somewhat unclear $(2,3)$.

IL-7 is a nonredundant cytokine essential for thymopoiesis, which is produced by a number of cell types including stromal cells (9), normal and malignant B cells (10), thymic epithelial cells (11), intestinal epithelial cells (12), BM-derived fibroblast-like cells (13), keratinocytes, and dendritic cells (14). IL-7 has pleiotropic effects on $\mathrm{T}$ cell homeostasis, such as enhancement of mature $\mathrm{T}$ cell survival (15-17), expansion of both peripheral $\mathrm{CD}^{+}$and $\mathrm{CD}^{+}$ $\mathrm{T}$ cells in T lymphocyte-depleted hosts (18), and mobilization of hematopoietic stem cells from the bone marrow to the peripheral circulation (19). Importantly, IL-7 enhances both HIV-1-specific $\mathrm{CD}^{+}$cytotoxic cellular activity of humans in vitro (20), as well as $\mathrm{CD}^{+} \mathrm{T}$ helper cell-dependent humoral responses and cytotoxic $\mathrm{CD}^{+} \mathrm{T}$ cell activity in mice immunized with HIV-1 envelope protein (21). Furthermore, Kaech et al. (22) demonstrated that, after a viral infection, a small population of effector $\mathrm{CD}^{+} \mathrm{T}$ cells had increased expression of the IL-7 receptor $\alpha$. These cells are the precursors of the memory $\mathrm{CD}^{+} \mathrm{T}$ cell pool that confers protective immunity, and their survival was shown to depend on IL-7. Napolitano et al. (23) reported that patients with AIDS have higher plasma levels of IL-7 than do other HIV-1-infected subjects. IL-7 levels were inversely correlated with $\mathrm{CD} 4^{+} \mathrm{T}$ lymphocyte loss and directly correlated with plasma HIV-1 viral load. Moreover, Llano et al. (24), using the same IL-7 detection kit, demonstrated that higher IL-7 plasma levels occur in HIV-1-infected individuals than 
Table 1

Clinical characteristics of the patients in this study

\begin{tabular}{|c|c|c|c|c|}
\hline $\begin{array}{l}\text { Patien } \\
\text { no. }\end{array}$ & $\begin{array}{l}\text { Antiviral } \\
\text { therapy }\end{array}$ & $\begin{array}{l}\text { Time period of plasma } \\
\text { viral RNA below } \\
50 \text { copies/ml (mo) }\end{array}$ & $\begin{array}{c}\text { CD4+ T lymphocyte } \\
\text { counts } \\
\left.\text { (cells } / \mathrm{mm}^{3}\right)\end{array}$ & $\begin{array}{c}\text { Initial plasma HIV-1 } \\
\text { RNA (copies/mI) } \\
\text { prior to therapy }\end{array}$ \\
\hline 1 & D4T/3TC/efavirenz & 63 & 548 & 677,000 \\
\hline 2 & AZT/3TC/efavirenz & 36 & 1,071 & 368,000 \\
\hline 3 & AZT/3TC/nelfinavir & 65 & 339 & 65,000 \\
\hline 4 & AZT/3TC/nelfinavir & 37 & 548 & 14,000 \\
\hline 5 & AZT/3TC/efavirenz & 64 & 565 & 200,000 \\
\hline 6 & 3TC/abacavir/efavirenz & Over 12 & 856 & N/A \\
\hline 7 & 3TC/AZT/ritonavir/indinavir & Over 12 & 273 & N/A \\
\hline 8 & AZT/3TC/efavirenz/nelfinavir & 50 & 760 & 26,500 \\
\hline 9 & D4T/3TC/efavirenz & 63 & 503 & 18,000 \\
\hline 10 & AZT/3TC/efavirenz & 40 & 586 & 56,000 \\
\hline 11 & DDI/D4T/lopinavir/ritonavir & Over 12 & 500 & N/A \\
\hline 12 & 3TC/D4T/saquinavir & Over 12 & 500 & $\mathrm{~N} / \mathrm{A}$ \\
\hline 13 & AZT/3TC/efavirenz & 48 & 400 & 900 \\
\hline 14 & AZT/3TC/efavirenz & 52 & 1,273 & 67,000 \\
\hline
\end{tabular}

N/A, not available; AZT, azidothymidine; 3TC, lamivudine; D4T, stavudine; DDI, didanosine.

latent viral reservoirs through activation of quiescent infected cells, promoting cell death and accelerating viral clearance, especially when combined with intensification of antiretroviral therapy (4).

We demonstrated that IL-7 was significantly more efficient than either IL-2 alone or even IL-2 in combination with phytohemagglutinin (PHA) in stimulating HIV-1 replication from $\mathrm{CD}^{+} \mathrm{T}$ cell/monocytedepleted PBMCs. We also found that IL-7 showed a positive trend for inducing proviral reactivation from resting $\mathrm{CD}^{+} \mathrm{T}$ lymphocytes from HIV-1-infected patients on suppressive HAART. Moreover, different viral isolates were induced by IL-7 and PHA/IL-2, which strengthens the hypothesis that combination therapy may be

in healthy donors $(9.4 \pm 5.7 \mathrm{pg} / \mathrm{ml}$ and $3.6 \pm 3.05 \mathrm{pg} / \mathrm{ml}$, respectively). Importantly, when HIV-1-seropositive subjects were grouped by $\mathrm{CD}^{+} \mathrm{T}$ cell count - less than $200,200-500$, or greater than 500 - higher values of plasma IL-7 were detected as compared with healthy donors $(12.26 \pm 5.9,6.67 \pm 4.1$, and $5.69 \pm 2.7 \mathrm{pg} / \mathrm{ml}$, respectively) (24). This probably represents a homeostatic response to lymphopenia, since the high levels of IL-7 decrease when the $\mathrm{CD}^{+} \mathrm{T}$ cell count increases after a HAART regimen is initiated. The authors hypothesized that IL-7 might play an important role in HIV-1 disease progression (23).

Of note, IL-7 was shown to be able to induce HIV-1 replication in vitro from PBMCs of HIV-1-infected individuals who were not treated with HAART (25-27), and to increase the expression of HIV-1 Tat mRNA in CD8-depleted PBMCs from chronically HIV-1infected patients (25). Moreover, recent in vitro studies indicate that IL-7 has minimal effects on T cell phenotype, while inducing substantial expression of latent HIV-1 (28-30), which suggests that IL-7 might be used as an additive therapy to HAART, not only for its immunological effects but also to purge HIV-1-latent reservoirs. IL-2 has already been used in a few clinical trials in association with HAART, either alone or in combination with OKT 3 (2-4). However, whether or not the addition of these immunostimulatory therapies was able to induce significant expression from a true HIV-1 latent reservoir is controversial. Distinct cytokines play critical roles in the regulation of $\mathrm{T}$ cell homeostasis and thus they may be beneficial in addition to HAART by virtue of improving the impaired immune response. Furthermore, these cytokines could induce the replication of different HIV-1 viral strains or archives out of proviral latency. This hypothesis prompted us to assess IL-7 as a therapeutic agent in inducing activation of latent HIV-1, to investigate its action on quiescent human $\mathrm{T}$ lymphocytes in infected patients on HAART, and to examine further the molecular and virological characteristics of the viruses induced by both IL-7 and IL-2.

New clinical approaches, such as stimulation therapy (or more precisely, immune-activation therapy), are now being investigated to try to achieve long-term remission or viral eradication. In fact, it has been speculated that this strategy aims to increase the turnover of more efficacious not only for the immunomodulatory effects but also to effectively stimulate different latent HIV-1 viral species.

\section{Results}

IL-7 promotes HIV-1 replication more efficiently than $P H A / I L-2$ from patients' PBMCs and resting CD4+ Tlymphocytes. The ability of different cell activators to induce the expression of persistent HIV-1 was evaluated on specific cell populations from 14 well-characterized patients on virally suppressive HAART. All the patients involved in this study received a stable HAART regimen for over a year, with plasma viral RNA levels below 50 copies/ml (Table 1).

As shown in Table 2, a total of 18 paired PBMC coculture reactions and 11 paired resting $\mathrm{CD}^{+} \mathrm{T}$ lymphocyte $\left(\mathrm{CD} 4^{+}, \mathrm{CD} 25^{-} /\right.$ HLA-DR-) cocultures were treated with IL-7 and PHA/IL-2 in parallel. Viral outgrowth was detected in 10 out of 18 (56\%) PBMC cocultures treated with IL-7, whereas viral outgrowth was detected in only 4 out of 18 (22\%) of those stimulated by PHA/IL-2 $\left(\chi^{2}=4.208, P<0.05\right)$. Of note, the 4 patients' cocultures that were positive for HIV-1 outgrowth with PHA/IL-2 were also positive for IL-7. However, unlike with IL-7, no viral outgrowth was detected from patients' PBMC cocultures (5 cultures) when IL-2 was used alone, without combining with PHA.

When pure resting $\mathrm{CD}^{+} \mathrm{T}$ cells were stimulated with IL-7 or PHA/ IL-2, HIV-1 replication was induced in 5 out of 11 (45.5\%) IL-7treated cultures and in 3 out of 11 (27.3\%) of those stimulated with PHA/IL-2. Two additional IL-7-treated resting CD4+ $\mathrm{T}$ lymphocyte cocultures were compared with unstimulated cultures and with cultures stimulated with IL-2 alone. IL-7 induced HIV-1 replication in 2 resting $\mathrm{CD}^{+} \mathrm{T}$ cell cocultures, while both unstimulated and IL-2-treated cultures remained negative until the end of the study. The average first appearance of viral production occurred at 3.5 weeks of culture. IL-7-induced viral outgrowth (4.1 weeks on average) required 2 weeks longer than outgrowth induced by PHA/IL-2 (2 weeks on average). However, both IL-7 and PHA/IL-2 yielded comparable levels of virus.

In summary, these results indicate that IL-7 is more effective than PHA/IL-2 or IL-2 alone in inducing the expression of persis- 
Table 2

HAART-persistent viral outgrowth by cellular activation

\begin{tabular}{lccccccc} 
Patient & Date of & \multicolumn{3}{c}{ CD8-depleted PBMC } & \multicolumn{3}{c}{ Resting T lymphocyte } \\
no. & blood & No stimulator & PHA/IL-2 & IL-7 & No stimulator & PHA/IL-2 & IL-7 \\
1A & $1 / 26 / 03$ & NEG & POS (2) & POS (2) & NEG & POS (1) & POS (4) \\
& $7 / 16 / 03$ & ND & ND & ND & NEG & ND & POS (5) \\
2A & $5 / 20 / 03$ & NEG & NEG & POS (5) & ND & ND & ND \\
& $8 / 19 / 03$ & NEG & POS (3) & POS (2) & ND & ND & ND \\
3 B & $5 / 27 / 03$ & POS (6) & POS (2) & POS (5) & ND & ND & ND \\
& $9 / 23 / 03$ & ND & ND & ND & NEG & NEG & POS (6) \\
& $11 / 11 / 03$ & NEG & POS (2) & POS (3) & ND & POS (2) & POS (5) \\
4A & $5 / 28 / 03$ & NEG & NEG & POS (5) & NEG & NEG & POS (6) \\
& $11 / 18 / 03$ & ND & NEG & NEG & NEG & NEG & NEG \\
5A & $3 / 10 / 03$ & NEG & NEG & NEG & NEG & NEG & NEG \\
& $10 / 21 / 03$ & ND & NEG & NEG & ND & POS (2) & NEG \\
6 & $3 / 12 / 03$ & NEG & NEG & NEG & NEG & NEG & NEG \\
7 & $3 / 19 / 03$ & NEG & NEG & NEG & NEG & NEG & NEG \\
8 & $5 / 15 / 03$ & ND & ND & ND & NEG & NEG & POS (3) \\
9 & $5 / 22 / 03$ & NEG & NEG & POS (6) & ND & ND & ND \\
$10 A$ & $7 / 21 / 03$ & ND & ND & ND & NEG & ND & POS (4) \\
& $9 / 17 / 03$ & NEG & NEG & POS (2) & ND & ND & ND \\
11 & $2 / 3 / 03$ & NEG & NEG & POS (4) & ND & ND & ND \\
12 & $1 / 23 / 03$ & NEG & NEG & NEG & ND & ND & ND \\
13 B & $5 / 21 / 03$ & NEG & NEG & NEG & ND & ND & ND \\
& $9 / 11 / 03$ & NEG & NEG & NEG & ND & ND & ND \\
& $11 / 4 / 03$ & NEG & NEG & POS (3) & ND & ND & ND \\
14 & $9 / 30 / 03$ & ND & ND & ND & ND & NEG & NEG \\
& & & & & & & \\
\hline
\end{tabular}

The underlined samples were used for virus genotype sequencing. The numbers in parenthesis indicate the week that HIV-1 p24 antigen first became positive. ${ }^{A}$ Cocultures were performed on 2 separate occasions on the same patient. ${ }^{\mathrm{B} C}$ Cocultures were performed 3 times for the same patient. POS, positive (HIV-1 p24 antigen level greater than $30 \mathrm{pg} / \mathrm{ml}$ ); NEG, negative. ND, not determined. the genotype of the viruses induced by both PHA/IL-2 and IL-7 - as well as their corresponding proviruses - from 4 patients. HIV-1 virion RNA was isolated from coculture supernatants (Table 3), and proviral DNA was isolated from the same patients' PBMCs and resting $\mathrm{CD}^{+} \mathrm{T}$ lymphocytes. Ten to fifteen clones for each proviral DNA or viral RNA sample were sequenced. Sequence contaminants were ruled out by comparison with common laboratory viral isolates.

The predicted amino acid sequences of proviral DNA and viral RNA were compared within each patient. Initial studies first revealed that potential inactivating mutations (i.e., premature stop codons and/or frameshifts) were present in proviral DNA Env clones, as well as in PHA/IL-2-induced viruses. In 3 out of 4 patients (patients 1, 3, and 4), amino acid sequences of proviral DNAs exhibited high diversity and most of the amino acid differences were localized in the V1/V2 regions, including multiple amino acid substitutions and length polymorphisms. On the contrary, extremely high homogeneity was observed in the corresponding Env gene of virion-encapsidated RNA in 11 out of 12 coculture tent viral reservoirs ex vivo from both PBMCs and resting $\mathrm{CD}^{+} \mathrm{T}$ lymphocytes of patients on fully virally suppressive HAART.

Phylogenetic analyses of the HIV-1 Env gp120 genes of IL-7-induced and PHA/IL-2-induced viral RNA. To investigate the phylogenetic relationships of replication-competent viruses and their proviral pool, we sequenced in entirety the viral envelope gp120 and obtained supernatants that were positive for HIV-1 p24 antigen. Rare single amino acid changes were observed and seemed to be recombinant forms of different cell-associated proviruses (data not shown).

In patient 1, IL-7-induced and PHA/IL-2-induced viral genotypes were quite different from each other. However, within each specific cytokine-induced group, viral sequences were found to

Table 3

Viral outgrowth (p24 antigen value, pg/ml) during coculture

\begin{tabular}{|c|c|c|c|c|c|c|c|c|c|}
\hline & & \multicolumn{8}{|c|}{ Time point of sample collection (wk) } \\
\hline & & 1 & 2 & 3 & 4 & 5 & 6 & 7 & 8 \\
\hline \multirow[t]{4}{*}{ Patient 1 (1/26/2003) } & PBMC/PHA\&IL-2 & 0 & 259 & $\underline{34,663}$ & 81,538 & 47,206 & $\underline{19,494}$ & 19,559 & 24,956 \\
\hline & PBMC/IL-7 & 0 & 226 & $\underline{6,394}$ & 32,163 & 39,519 & $\underline{11,717}$ & 22,686 & 19,766 \\
\hline & Resting T cells/PHA\&IL-2 & 105 & $\underline{20,940}$ & $\overline{28,441}$ & 15,941 & 20,741 & $\underline{25,606}$ & 21,942 & 27171 \\
\hline & Resting T cell/IL-7 & 0 & 0 & 0 & 0 & 30 & $\underline{242}$ & 1,430 & 2,433 \\
\hline \multirow[t]{2}{*}{ Patient 2 (8/19/2003) } & PBMC/PHA\&IL-2 & 0 & 0 & 66 & $\underline{4,939}$ & $\underline{5,040}$ & $\overline{4,553}$ & $\overline{4,602}$ & 4,785 \\
\hline & PBMC/IL-7 & 0 & 72 & 2,278 & $\overline{4,826}$ & $\overline{4,836}$ & 4,528 & 4,878 & 4,526 \\
\hline \multirow[t]{4}{*}{ Patient 3 (11/11/2003) } & PBMC/PHA\&IL-2 & 0 & 4,655 & 4,836 & $\overline{5,365}$ & $\overline{5,202}$ & $\underline{4,448}$ & 5,127 & 5,569 \\
\hline & PBMC/IL-7 & 0 & 0 & 46 & $\overline{4,961}$ & 5,205 & $\overline{5,310}$ & 5,044 & 5,539 \\
\hline & Resting T cells/PHA\&IL-2 & 0 & 4,855 & 4,774 & $\underline{5,457}$ & 5,823 & $\underline{5,205}$ & 5,360 & 5,428 \\
\hline & Resting T cell/IL-7 & 0 & 0 & 0 & 0 & $\underline{3,933}$ & $\underline{5,152}$ & 5,424 & 5,238 \\
\hline \multirow[t]{3}{*}{ Patient 4 (5/28/2003) } & PBMC/IL-7 & 0 & 0 & 0 & 0 & 143 & 3,362 & $\underline{26,000}$ & 32,250 \\
\hline & Resting T cell/IL-7 & 0 & 0 & 0 & 0 & 0 & $\overline{1,695}$ & $\overline{39,750}$ & 34,750 \\
\hline & Resting T cells/PHA\&IL-2A & 0 & 0 & 5,631 & 4,100 & 5,989 & $\overline{4,028}$ & 3,218 & 2,033 \\
\hline
\end{tabular}

The supernatant samples underlined were used for viral gene phylogenetic analysis. Viral RNA was isolated from indicated supernatant samples and PCR was performed at least twice. Mixed PCR products were used for TA cloning in order to detect HIV-1 envelope sequence divergence in replication-competent viral populations. ACoculture was performed on 10/4/2001. 
be homogeneous despite being from of $\mathrm{PBMC}$ and resting $\mathrm{CD} 4^{+}$ $\mathrm{T}$ lymphocyte origin. In the full-length 300-AA region V1-V5 of HIV-1 gp120 we observed 5 single amino acid changes in 5 separate clones ( 2 in $\mathrm{V} 1 / \mathrm{V} 2,1$ in $\mathrm{C} 2,1$ in $\mathrm{V} 3$, and 1 in the $\mathrm{C} 3$ region) and 4 amino acid deletions in another clone (in the $\mathrm{C} 3$ region), from a total of 8 clones derived from IL-7-induced viral RNA from resting $\mathrm{CD}^{+} \mathrm{T}$ lymphocytes. PBMC/IL-7-stimulated viruses contained 2 single amino acid changes in 2 of the 6 clones ( 1 in $\mathrm{V} 3$ and the other in the $\mathrm{C} 3$ region). There were 3 single amino acid changes ( 2 in $\mathrm{V} 1$ and 1 in the $\mathrm{C} 3$ region) scattered in 3 of the total 8 clones in resting $\mathrm{CD}^{+} \mathrm{T}$ cell/IL-2-stimulated viruses. Similarly, high homogeneity was observed in PBMC/IL-7-stimulated viruses for patients 2, 3, and 4, resting CD4 ${ }^{+} \mathrm{T}$ cell/IL-7-induced viruses for patients 3 and 4, and PBMC/IL-2-induced viruses for patients 2, 3, and 4. Surprisingly, these initial analyses suggested that certain restricted proviral quasispecies had been activated by each specific stimulator.

To further analyze in detail the genetic diversity of the recovered viruses by treatment with different cytokines, and to determine the potential importance in inducing divergent proviral archives, we generated rooted phylogenetic trees using the HIV-1 gp120 V1-V5 nucleotide sequences for proviruses and induced viruses from each of the 4 patients (Figure 1). We evaluated the phylogenetic relationships among intrapatient sequence sets of PBMC or resting $\mathrm{CD}^{+} \mathrm{T}$ lymphocyte proviral DNA and cell-free viral RNA induced by IL-7 or PHA/IL-2. Of note, the laboratory viral strain HXB2 segregated distantly from all patients' sequences.

The phylogenetic tree for patient 1 reveals an interesting intrapatient sequence relationship. There are 2 primary branches, as shown in Figure 1A. The top branch represents viral RNA from IL-7-stimulated cocultures, and the bottom branch illustrates viral RNA from PHA/IL-2-stimulated cocultures. Proviral DNAs from PBMCs and resting $\mathrm{CD}^{+} \mathrm{T}$ lymphocytes were detected on both branches. These data indicated that IL-7 and PHA/IL-2 induced the replication of distinct viruses that belonged to different subpopulations that were contained in the same proviral pool. Of interest, a similar phenomenon was observed for patient 2 , as shown in Figure 1B. In patients 1 and 3 (Figure 1, A and C), IL-7 induced the replication of very similar HIV-1 isolates (i.e., segregated in the same branch of the phylogenetic tree) regardless of whether PBMCs or pure resting $\mathrm{CD}^{+} \mathrm{T}$ lymphocytes were stimulated, showing a highly provirus-specific effect. Interestingly, in patient 3, IL-7 and PHA/IL-2 induced the growth of 2 distinct viruses, on separate branches, solely from resting $\mathrm{CD}^{+} \mathrm{T}$ lymphocytes. This suggests a selective effect on a true latent HIV-1 reservoir not contaminated by the presence of activated CD $4^{+} \mathrm{T}$ lymphocytes in PBMCs, known to produce low levels of HIV-1 replication. We were able to show that the separation of these 2 distinct viruses in 2 separate branches could be found, in patient 3 , even when the entire full-length HIV-1 genome was sequenced and analyzed (data not shown). In patient 3 , envelope sequences also derived from full-length viral sequencing fit into the subbranches of the tree based on PHA/IL-2 versus IL-7 treatment (Figure 1C). Similarly, for patient 4, viral populations were again clustered tightly in quite separate subbranches, as shown in Figure 1D. Finally, intrastimulus viral quasispecies were also analyzed. IL-7-induced virus showed high homogeneity in 3 out of 4 patients, while much more diversity was observed in PHA/ IL-2 virus populations (data not shown).

The segregation of these HIV-1 viral populations induced by diverse stimulators highlights that proviral reactivation by different cytokines may be from differing proviral quasispecies exist- ing in the same or different latently infected CD4 $4^{+} \mathrm{T}$ lymphocyte subpopulations. These results suggest that more than one stimulator might be needed, in combination, to purge or deplete HIV-1 reservoirs in a more efficient and complete manner.

IL-7-mediated viral replication is in part dependent on activation of resting $C D 4^{+}$T lymphocytes. Cytokine treatment can alter the activation state of the host cells and thus change patterns of viral replication. Our findings that IL-7 induced expression of latent virus effectively from patients' PBMCs and resting $\mathrm{CD}^{+}{ }^{+} \mathrm{T}$ lymphocytes suggested that this cytokine activated the latently infected peripheral resting $\mathrm{CD}^{+} \mathrm{T}$ lymphocytes harboring HIV-1 proviral DNA. The expression of various activation and proliferation markers, including CD25, CD69, HLA-DR, and Ki-67, were then assessed. Resting $\mathrm{CD}^{+} \mathrm{T}$ lymphocytes were purified from healthy donors' peripheral blood and treated with IL-7 alone $(20 \mathrm{ng} / \mathrm{ml})$ for 14 days or PHA $(5 \mu \mathrm{g} / \mathrm{ml}$ for 48 hours) plus IL-2 $(20 \mathrm{ng} / \mathrm{ml})$ for 3 days. As shown in Figure 2A, we observed an increased number of cells expressing the activation marker CD25 in IL-7-treated resting T cell populations, which was associated with an increase of the proliferation marker Ki-67, but not with an increase in HLA-DR or CD69 (data not shown). A high level of CD25 expression (36.2\%) was observed on day 1 and increased at the following time points $(71.4 \%$ on day 7 after treatment), as compared with untreated cells (data not shown). Ki-67 expression peaked on day 7 (13\%) and was followed by a rapid decline (data not shown). Intracellular Ki-67 staining demonstrated the proliferation of IL-7-treated resting $\mathrm{CD}^{+} \mathrm{T}$ lymphocytes, in agreement with previous studies (31-36). Figure $2 B$ illustrates the cell activation efficiency when treated with PHA and then IL-2. These results suggest that the partial activation and proliferation of the resting T lymphocyte population treated with IL-7 may contribute to the induction of HIV-1 replication out of latency.

To further define the extent of cellular activation, we tested the effect of IL-7 on inducing cell-cycle progression. Highly purified resting $\mathrm{CD}^{+} \mathrm{T}$ lymphocytes were cultured in media alone or in the presence of IL-7 for 7 days. As shown in Figure 2C, an increase in cellular RNA was observed on day 3 after treatment and, on day 7 , $17 \%$ of the cells progressed into the $S$ and $G_{2} / M$ phase of the cell cycle (data not shown). These data lead us to further suggest that IL-7-induced cellular proviral expression could be partially based on its effect on cell activation and cell-cycle progression.

To test whether IL-7-induced resting $\mathrm{T}$ lymphocyte activation was an incidental cross-reactive effect of autocrine-mediated release of secondary cytokines from the IL-7-stimulated resting $\mathrm{CD}^{+} \mathrm{T}$ lymphocytes, we used a proteomics microarray in coculture supernatants of both IL-7-treated and untreated resting $\mathrm{T}$ lymphocytes to test for the presence of 42 cytokines. We did not detect any significant difference in endogenous cytokine release (data not shown). These results suggest a potential direct effect of IL-7 in inducing resting CD4 ${ }^{+} \mathrm{T}$ lymphocyte activation without intermediate interaction of other released cytokine(s).

Infectivity of PHA/IL-2-induced and IL-7-induced viruses. Next, we examined the infectivity and replication-competence of both PHA/IL-2-induced and IL-7-induced viruses. The HIV- $1_{\mathrm{NL} 4-3}$ isolate was used as a positive control. The viruses were normalized by HIV-1 p 24 antigen levels to an input concentration of $5 \mathrm{ng} / \mathrm{ml}$ per $10^{6}$ cells. The kinetics of HIV-1 replication was measured by HIV-1 p24 antigen detection in triplicate culture supernatants. As shown in Table 4, both PHA/IL-2-induced and IL-7-induced virions have comparable infectivity with the laboratory strain NL4-3. These data indicate that the cytokine-induced viruses are fully 


\section{A}
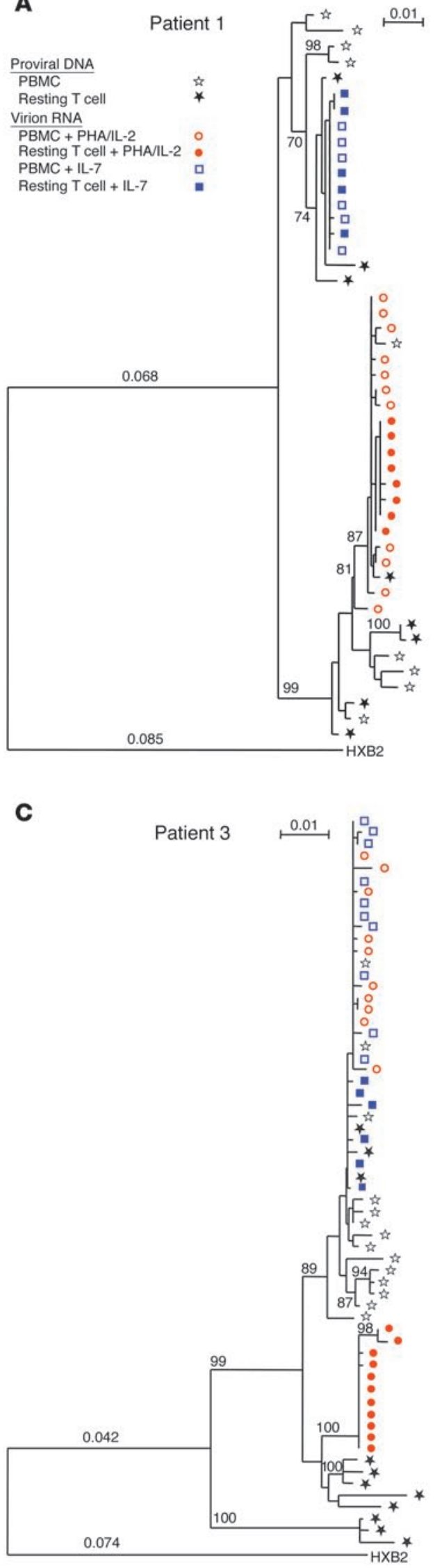

B
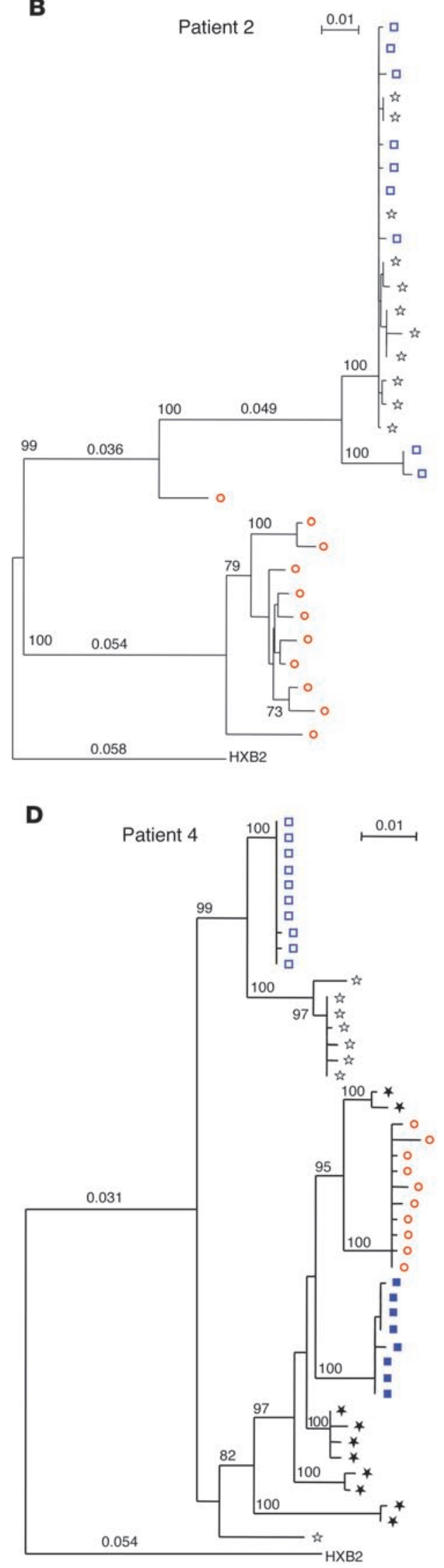

Figure 1

Phylogenetic analyses of HIV-1 envelope gene sequences of proviral DNA and cytokine-induced virion RNA from the same cell populations. The full-length of gp120 $\mathrm{V} 1$ to $\mathrm{V} 5$ regions were cloned and sequenced directly from proviral DNA of PBMCs and purified, resting CD4+ T lymphocytes, and IL-7 or PHA/IL-2-induced virion RNA for 4 patients (numbers 1-4, A-D). Proviral DNA sequences are presented by black stars (open stars for those strains from PBMC and filled for those of resting $\mathrm{CD}_{4}{ }^{+} \mathrm{T}$ lymphocytes). IL-7-induced viral RNA sequences are indicated by blue squares (open squares for PBMC and IL-7-induced and filled squares for resting CD4+ $\mathrm{T}$ lymphocyte and IL-induced). PHA/IL-2induced viral RNA sequences are indicated by red circles (open circles for those induced by PBMC with PHA/IL-2 and filled circles for those induced by resting CD4+ T- lymphocyte with PHA/IL-2). Growth of patient 4's virus from PBMCs with PHA/IL-2 was from $10 / 04 / 2001$. All sequences are shown with HXB2 (GenBank accession no. K03455) as the reference outgroup. Branch lengths are drawn in proportion to the number of nucleotide substitutions per site, and bootstrap probabilities (1,000 iterations) exceeding $70 \%$ for each node are noted. 
A
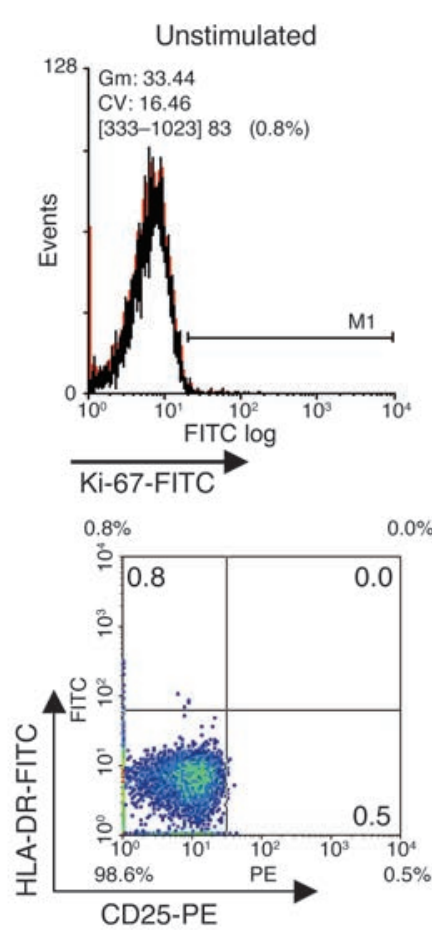

B

Untreated

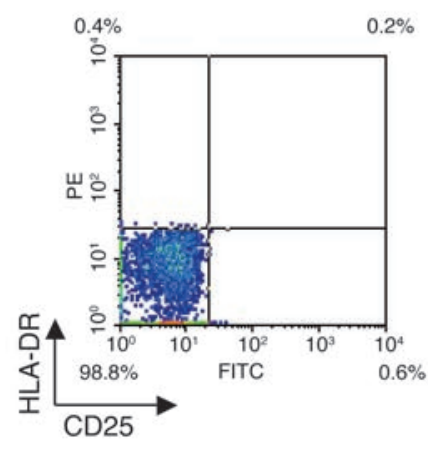

C

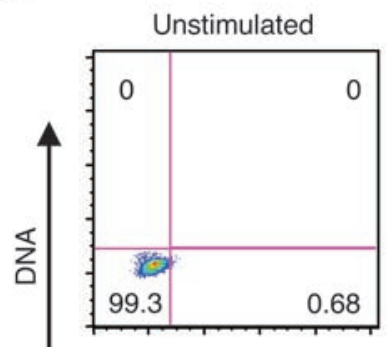

IL-7-stimulated
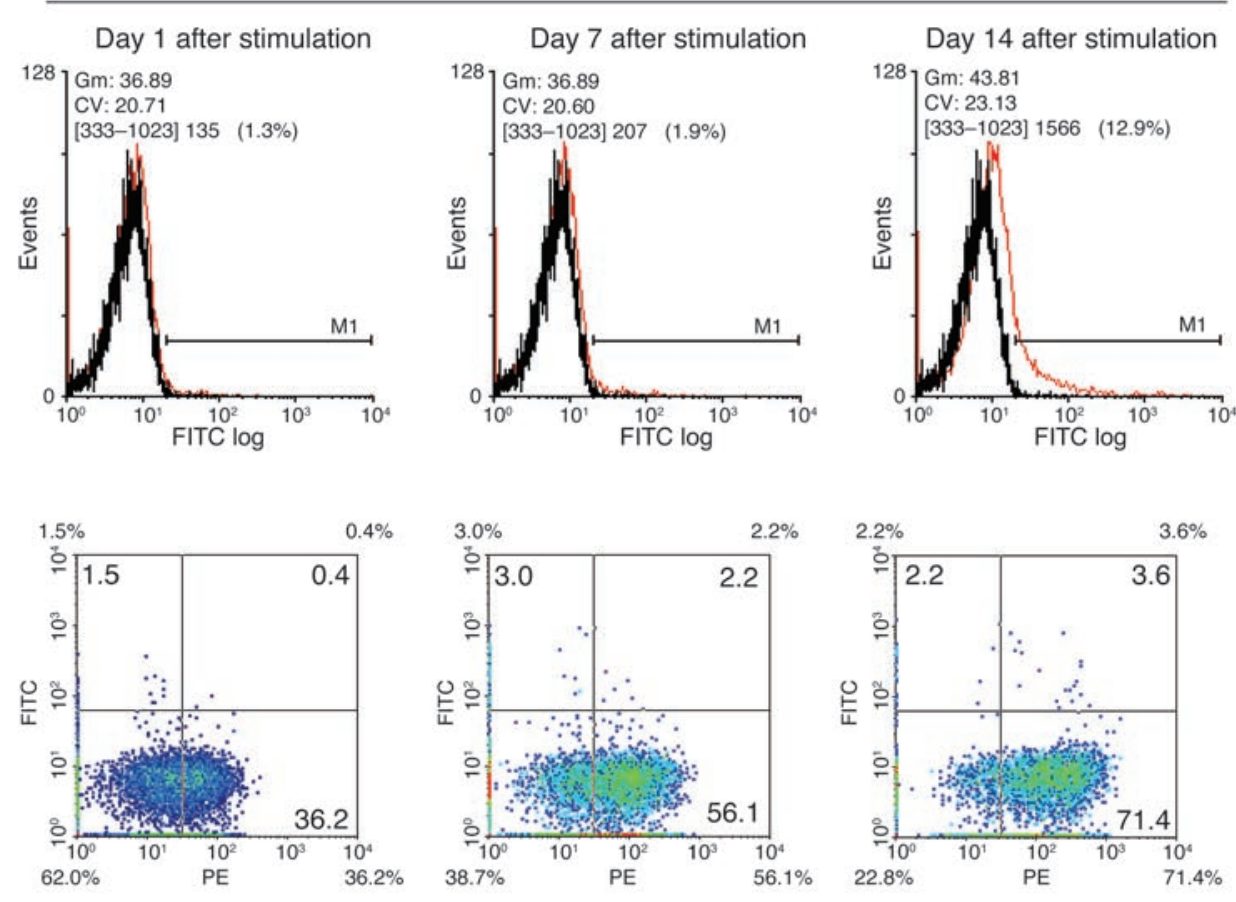

Day 14 after stimulation

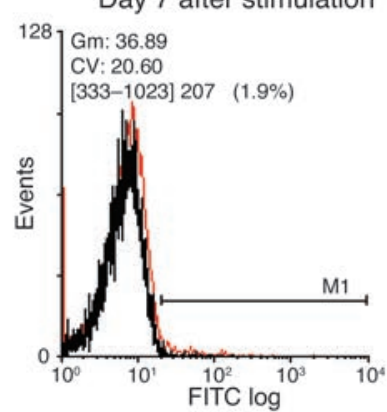

${ }^{128}$ ] Gm: 43.81

CV: 23.13

[333-1023] $1566 \quad(12.9 \%)$

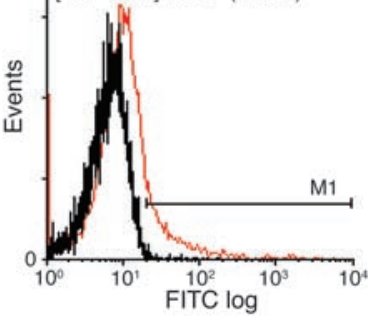

Treated with PHA (24 h) and IL-2 (48 h)

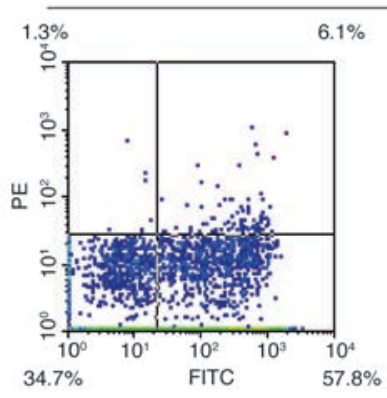

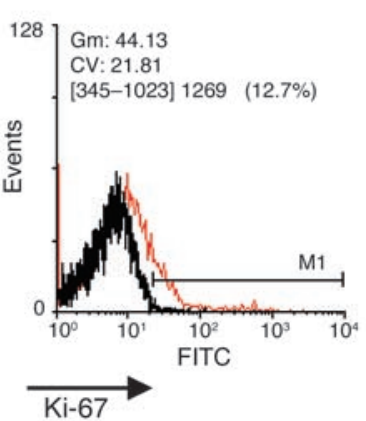

IL-7-treated
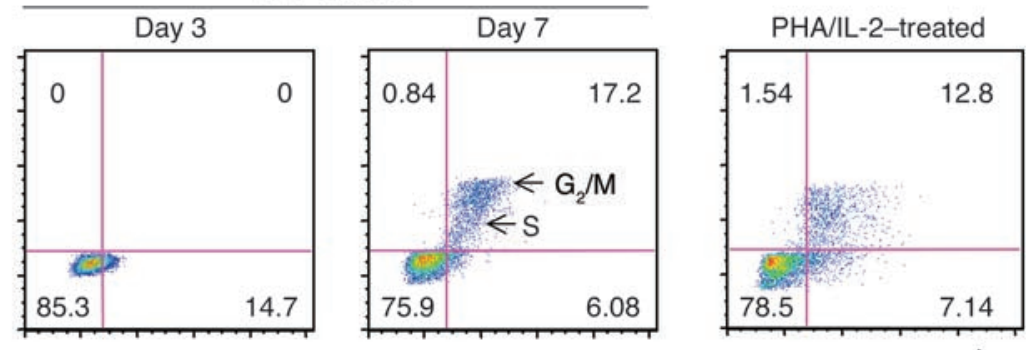

RNA

Figure 2

Stimulatory patterns of resting CD4+ T lymphocytes by IL-7. (A and B) Detection of cell activation markers in IL-7-treated or PHA/IL-2-treated human resting CD4+ $\mathrm{T}$ lymphocytes. Freshly isolated resting CD4+ T lymphocytes stimulated with IL-7 or PHA/IL-2 were stained with FITC-conjugated anti-KI-67, anti-HLA-DR, and PE-conjugated anti-CD25. Three independent experiments were performed, of which one representative is illustrated. Gm, geometric mean; CV, coefficient of variance. (C) Effects of IL-7 on the cell cycle of human peripheral blood resting CD4+ T lymphocytes. IL-7 alone or PHA/IL-2-stimulated, initially resting CD4+ T lymphocytes are shown with the cell-cycle status indicated in each quadrant. DNA is depicted on the vertical axis and RNA is shown on the horizontal axis. Positions indicating stages in the cell cycle are illustrated in the third panel. The cell cultures either alone or in the presence of IL-7 were continued for a full 7 days. PHA/IL-2-stimulated cells were treated with PHA $(5 \mu \mathrm{g} / \mathrm{ml})$ for 48 hours and then IL-2 (10 $\mathrm{ng} / \mathrm{ml})$ for 3 days. 


\section{Table 4}

Comparison of the replication competence of viruses

\begin{tabular}{|c|c|c|c|c|c|c|}
\hline \multirow{3}{*}{ HIV-1 viral input } & \multicolumn{5}{|c|}{ HIV-1 p24 antigen expression } & \\
\hline & \multicolumn{3}{|c|}{ Day 7 (after infection) } & \multicolumn{3}{|c|}{ Day 14 (after infection) } \\
\hline & IL-7 virus & PHA/IL-2 virus & NL4-3 & IL-7 virus & PHA/IL-2 virus & NL4-3 \\
\hline 1:1 (5 ng/ml of HIV-1 p24) & +++ & ++++ & ++++ & ++++ & ++++ & ++++ \\
\hline $1: 4$ & + & ++++ & ++++ & ++++ & ++++ & ++++ \\
\hline $1: 16$ & - & ++ & + & ++++ & ++++ & +++ \\
\hline
\end{tabular}

replication-competent and capable of perpetuating the spread of HIV-1 to uninfected cells.

IL-7 and HIV-1 long terminal repeat transactivation. Finally, to evaluate and precisely isolate the potential differential effects of the stimulatory regimens on HIV-1 long terminal repeat-mediated (HIV-1 LTR-mediated) transcription, we performed gene reporter assays. These assays demonstrated that IL-7, at 6 hours after addition, induced HIV-1 LTR activity by only 2 -fold at a concentration of $100 \mathrm{ng} / \mathrm{ml}$, while at lower concentrations (i.e., $10-20 \mathrm{ng} / \mathrm{ml}$ ), IL-7 demonstrated no effect. IL-2 alone (10 ng/ml), 6 hours after addition, did not have any effect on HIV-1 LTR activity. Both PMA and PHA $(10 \mathrm{ng} / \mathrm{ml}), 6$ hours after addition, significantly induced HIV-1 LTR activity by approximately 25 -fold (data not shown). These results suggest that, at least in this specific HIV-1 LTR transactivation assay, IL-7 exerts only a modest effect on LTRdirected transcription, and thus this may not represent the molecular pathway involved with more robust stimulation of archival proviruses in the PBMCs of patients on virally suppressive HAART.

Of note, differences in specific induction of select proviruses by divergent cytokines could be related to the existence of diverse proviral quasispecies in distinct subpopulations of resting $\mathrm{CD} 4^{+} \mathrm{T}$ lymphocytes, such as $\mathrm{CD}^{+} / \mathrm{CD} 45 \mathrm{RA}^{+}$naive and $\mathrm{CD}^{+} / \mathrm{CD} 45 \mathrm{RO}^{+}$ memory $\mathrm{T}$ lymphocytes, or to regulation of viral expression by specific cytokines, possibly through their effects on viral transcription. As such, we sequenced the LTRs of replication-competent viruses induced by IL-7 and PHA/IL-2 in certain individuals. Nonetheless, there were no specific nucleotide sequence differences in the LTR U3 regions from paired cytokine-induced viruses (i.e., PHA/IL-2-induced versus IL-7-induced) in the 2 patients analyzed (data not shown).

\section{Discussion}

The addition of $\mathrm{T}$ cell-activating agents to potent antiretroviral therapy has been proposed as a possible strategy to purge cellular reservoirs in long-lived, HIV-1-infected quiescent $\mathrm{CD}^{+} \mathrm{T}$ lymphocytes. IL-2 administration is one of the most extensively studied immune-based therapies in HIV-1-infected individuals (7). IL-2 in combination with HAART has led to $\mathrm{CD} 4^{+} \mathrm{T}$ lymphocyte expansion, although it had modest effects on purging the HIV-1 reservoir either alone or in combination with OKT-3. IL-7 has been proposed as a possible supplement to HAART (28), not only for its immunomodulatory properties and its crucial role in $\mathrm{T}$ cell homeostasis, but also to deplete HIV-1 reservoirs by stimulating the pool of latently infected cells.

In the present study, we investigated the effects of IL-7 and PHA/ IL-2 on HIV-1 replication in $\mathrm{CD}^{+} \mathrm{T}$ cell/monocyte-depleted PBMCs and resting $\mathrm{CD}^{+} \mathrm{T}$ lymphocytes freshly isolated from HIV-1-infect- ed individuals on virally suppressive HAART and with plasma HIV-1 RNA levels lower than 50 copies $/ \mathrm{ml}$. We demonstrated that IL-7 is more effective than IL-2 in enhancing HIV-1 proviral reactivation, not only from $\mathrm{CD}^{+} \mathrm{T}$ cell/monocyte-depleted PBMCs but also from resting $\mathrm{CD}^{+} \mathrm{T}$ lymphocytes. IL-7 was able to induce HIV-1 replication in $56 \%$ of $\mathrm{CD}^{+} \mathrm{T}$ cell/monocyte-depleted $\mathrm{PBMCs}$ and in $45.5 \%$ of pure populations of resting $\mathrm{CD}^{+} \mathrm{T}$ lymphocyte cocultures. Importantly, PHA/IL-2 stimulation induced HIV-1 replication in only $22 \%$ and $27.3 \%$ of $\mathrm{CD}^{+} \mathrm{T}$ cell/monocyte-depleted PBMCs and resting $\mathrm{CD}^{+} \mathrm{T}$ lymphocyte cocultures, respectively. Moreover, in 6 patients when IL-7 was compared with IL-2 alone, we found that the latter did not induce HIV-1 replication in any of the coculture assays, while 3 out of 5 cocultures treated with IL-7 were positive for viral outgrowth (data not shown).

In a previous study in the pre-HAART era, IL-7 was shown to upregulate HIV-1 replication from PBMCs of HIV-1-infected individuals ex vivo, although these subjects were not on HAART, and thus the noise of high levels of viral load and continuous viral replication prevented further analysis regarding the possible effects on true HIV-1 latency (25). In our study, the effects of IL-7 on HIV-1 replication were tested in both $\mathrm{CD}^{+} \mathrm{T}$ cell/monocyte-depleted $\mathrm{PBMCs}$ and pure populations of resting $\mathrm{CD} 4^{+} \mathrm{T}$ lymphocytes, with complementary results. Moreover, our present data indicate that IL-7 had a direct effect on resting $\mathrm{CD}^{+} \mathrm{T}$ lymphocyte-associated viral outgrowth. This rules out the possibility that contaminating cells in the $\mathrm{CD}^{+} \mathrm{T}$ cell/monocyte-depleted PBMC cocultures may have interfered with the induction of HIV-1 replication, either directly or through the release of cytokines or chemokines. Furthermore, potentially interfering secondary cytokines were not detected in IL-7-treated resting $\mathrm{CD}^{+} \mathrm{T}$ cell coculture supernatants, via a proteomics approach. Thus, these results strongly suggest that IL-7 alone is more efficient than PHA/IL-2 in inducing HIV-1 replication directly from latently infected cells of HIV-1infected subjects on HAART. In future studies, it will be interesting and possibly important to combine IL-7 with other cytokines including, but not limited to, IL-2.

We hypothesized that IL-7 and PHA/IL-2 stimulation might induce the replication of different viral strains. As such, the HIV-1 envelope gp120 V1-V5 region was sequenced and analyzed. Interestingly, the phylogenetic trees revealed that in patients 1 and 2 there were 2 primary branches showing distinct segregation of sequences with regard to PHA/IL-2-induced and IL-7-induced viruses (Figure 1, $\mathrm{A}$ and $\mathrm{B}$ ). Patient 3 revealed distinct PHA/IL-2-induced versus IL-7-induced virions from solely resting CD $4^{+} \mathrm{T}$ lymphocytes (Figure 1C). In patient 4, 2 viral populations were also clustered tightly in separate sub-branches (Figure 1D). Cytokine-induced replication-competent viruses were contained in the corresponding 
proviral pool of PBMCs and/or pure resting $\mathrm{CD}^{+} \mathrm{T}$ lymphocytes. These results strongly indicated that different cytokines had induced divergent proviral DNA expression from the CD4 ${ }^{+} \mathrm{T}$ lymphocyte proviral archive. It remains a formally possible hypothesis that the existence of diverse proviral quasispecies may occur in distinct subpopulations of resting $\mathrm{CD}^{+}{ }^{+} \mathrm{T}$ lymphocytes, such as $\mathrm{CD} 4^{+} /$ $\mathrm{CD}_{45 \mathrm{RA}^{+}}$naive and $\mathrm{CD}^{+} / \mathrm{CD}_{4} 5 \mathrm{RO}^{+}$memory $\mathrm{T}$ lymphocytes. In addition, regulation of viral expression by specific cytokines, possibly through their effects on viral transcription or at other sites of the lentiviral life cycle, may have led to viral strain-specific induction.

Resting $\mathrm{CD}^{+} \mathrm{T}$ lymphocytes are considered a major HIV-1 reservoir (1). Thus, we investigated whether IL-7 had an effect on the activation or proliferation of these cells, which might be involved in the induction of HIV-1 from latency. We observed an increased expression of CD25 in the IL-7-treated resting CD $4^{+} \mathrm{T}$ lymphocyte population in accordance with previous results, which further demonstrated that $\mathrm{CD} 4^{+} / \mathrm{CD} 25^{+} \mathrm{T}$ cells actively produce virus in vitro (37). The expression of T cell activation markers CD69 and HLA-DR was not modified by IL-7. Moreover, IL-7 induced an increase of the proliferation marker Ki-67 in resting $\mathrm{CD}^{+} \mathrm{T}$ lymphocytes, as well as their progression into $S$ and $\mathrm{G}_{2} / \mathrm{M}$ phases of the cell cycle.

In the interest of evaluating the potential use of IL-7 in humans, in vivo studies in a SCID- $b u$ mouse model (28) and in macaques (31) have been performed, and the immunological and virological effects of IL-7 were assessed. In SIV-infected monkeys, a remarkable increase in $\mathrm{CD}^{+} \mathrm{T}$ cells, particularly $\mathrm{CD}^{+}$and $\mathrm{CD}^{+}$naive $\mathrm{T}$ cells, was demonstrated. Furthermore, the absolute number of $\mathrm{CD}^{+}$ HLA-DR ${ }^{+}$cells was augmented and correlated with an increase of the absolute number of Ki-67-positive cells (31). Surprisingly, IL-7 did not alter the plasma viral load levels, in accordance with a previous study by Fry et al. (38), in which antiretroviral therapy was administered. On the other hand, in the SCID- $b u$ mouse model, IL-7 effectively stimulated the pool of latently HIV-1 infected cells while having minimal effects on $\mathrm{T}$ cell phenotype (28). Of note, IL-7 has been used in combination with an HIV-1-specific immunotoxin, with some success, to activate and deplete viral residual disease, also in SCID- $b u$ mice (39).

The present studies provide direct evidence that exogenous IL-7 upregulated the expression of HIV-1 in latently infected cells from HIV-1-infected individuals on suppressive HAART, more effectively than did PHA/IL-2 or IL-2 alone. In previous studies, 1 cytokine alone rarely had robust effects on activating proviruses from latency (30). Of importance, different viral quasispecies from the same cellular latency pool were induced. The present findings suggest that cytokine combinations might be required in addition to HAART to stimulate diverse HIV-1 proviral quasispecies from latency. Not only is IL-7 alone more potent than PHA/IL-2, but it is important to point out that PHA cannot be used in a regimen for humans. Intensification therapy added to HAART, to attempt to inhibit viral spread of stimulated virions, and the immunomodulatory effects of IL-2 and IL-7, should now be taken into consideration (40), as they may act synergistically in controlling cytokine-induced reactivation of HIV-1. Further studies are needed to now rationally design clinical protocols to deplete or purge latent HIV-1 residual disease with these agents (41).

\section{Methods}

Study subjects. Fourteen HIV-1-infected individuals on stable virally suppressive HAART were enrolled in this study. All patients had at least 2 ultrasensitive RT-PCR results demonstrating plasma viral RNA levels below
50 copies $/ \mathrm{ml}$, and had undetectable plasma viral loads for at least a year prior to the study. Blood samples were obtained by peripheral phlebotomy. Each subject signed a consent form that was approved by the Institutional Review Board of Thomas Jefferson University.

Resting $\mathrm{CD}^{+}$Tlymphocyte isolation. Resting $\mathrm{CD} 4^{+} \mathrm{T}$ lymphocytes were isolated using a Miltenyi automated cell-isolation device (autoMACS, Miltenyi cell-separation device; Biotech Inc.). Patients' PBMCs were separated from blood plasma by discontinuous Ficoll-Hypaque (Sigma-Aldrich) centrifugation. PBMCs were depleted of $\mathrm{CD} 8^{+}, \mathrm{CD} 14^{+}, \mathrm{CD} 19^{+}, \mathrm{CD} 56^{+}, \mathrm{CD}^{2} 6^{+}, \mathrm{CD}_{123^{+}}$, $\mathrm{CD} 235 \mathrm{a}^{+}, \mathrm{CD} 16^{+}$, and anti-TCR $\gamma / \delta^{+}$cells by direct immunomagnetic labeling, using antibodies against their respective surface markers (Miltenyi Inc.). The negative fraction was then depleted of $\mathrm{CD} 25^{+}$and HLA-DR ${ }^{+}$ cells by direct immunomagnetic conjugation and further separation. The

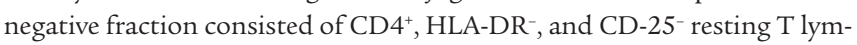
phocytes (resting $\mathrm{CD} 4^{+} \mathrm{T}$ lymphocytes).

HIV-1-seronegative donors' PBMCs were depleted of CD8 ${ }^{+} \mathrm{T}$ lymphocytes by binding with magnetic beads conjugated with anti-CD8 antibody (CD8 Dynabeads from Dynal). This process decreases the fraction of CD8 ${ }^{+}$ T lymphocytes in the PBMCs from approximately $20-30 \%$ to $3-5 \%$, as analyzed by flow cytometry (42). Macrophages and their precursors were depleted from PBMCs by incubating the samples overnight to allow these cells to attach to the plastic plates. The remaining PBLs were then stimulated with $5 \mu \mathrm{g}$ of PHA per milliliter (Sigma-Aldrich) and $10 \mathrm{ng} / \mathrm{ml}$ of IL-2 (Invitrogen Corp.).

Cell culture conditions and coculture assays. Patients' PBMCs or isolated resting $\mathrm{CD}^{+} \mathrm{T}$ lymphocytes were cultured in RPMI-1640 medium with $10 \%$ FCS and penicillin plus streptomycin at $37^{\circ} \mathrm{C}$ for 8 to 10 weeks in the presence of 10 or $20 \mathrm{ng} / \mathrm{ml}$ of IL-7 (R\&D Systems Inc.), as described previously $(25,28,39)$, or prestimulated with $5 \mu \mathrm{g} / \mathrm{ml}$ of PHA and then $5-10 \mathrm{ng} / \mathrm{ml}$ of IL-2 $(2,30)$. Once a week, half the medium was replaced with fresh medium and half the cells were replaced with fresh PBMC from HIV-1 seronegative subjects. HIV-1 p24 antigen was measured in the supernatants by an ELISA (Dupont). Positive cultures were defined as those demonstrating at least $30 \mathrm{pg} / \mathrm{ml}$ of HIV-1 p24 antigen in the culture supernatant. All procedures were performed under biosafety level- 3 conditions to minimize the possibility of cross-contamination.

Flow cytometry for surface and intracellular cell markers. To assess the purity of the cell populations and the expression levels of cell activation markers after cytokine treatment, we stained $5 \times 10^{5}$ cells with monoclonal antibodies to specific cell surface markers (BD Biosciences - Pharmingen) against HLA-DR (also known as major histocompatibility complex II), CD25 (IL-2 $\alpha$ receptor; i.e., surface activation marker), CD14 (macrophage marker), CD3 (T lymphocyte marker), CD69 (an early marker of T cell activation), or intracellular marker against Ki-67 (proliferation marker). For staining, anti-HLA-DR and Ki-67 monoclonal antibodies were conjugated directly to FITC; anti-CD25 was conjugated directly to PE, and anti-CD69 was conjugated directly to peridinin chlorophyll protein. The staining was performed on ice for 30 minutes, then it was subsequently washed 3 times with phosphate-buffered saline $(1 \times)$ and fixed in $2 \%$ paraformaldehyde. Intracellular Ki-67 staining was performed by initially fixing and permeabilizing the lymphocytes with FACS Cytofix/Cytoperm solution (BD), followed by intracellular staining with the Ki-67-FITC antibody. Data were accumulated on a BD FACSCalibur flow cytometer and subsequently analyzed with the Flowjo Software Program (TreeStar Inc.).

Cell-cycle analyses. Cells $\left(5 \times 10^{5}\right.$ under each set of conditions) were stained for DNA and RNA content with 7-amino-actinomycin D and pyronin Y, respectively (43). Briefly, cells were suspended in $475 \mu$ of nucleic acid staining solution $(0.15 \mathrm{M} \mathrm{NaCl}$ in $0.1 \mathrm{M}$ phosphate-citrate buffer containing $5 \mathrm{mM}$ sodium EDTA (Sigma-Aldrich) and 0.5\% BSA (Sigma-Aldrich), $\mathrm{pH} 6.0$ containing $0.03 \%$ saponin (Sigma-Aldrich). 7 -amino-actinomycin D 
(Sigma-Aldrich) was added at a final concentration of $20 \mu \mathrm{M}$. Cells were incubated for 30 minutes and then cooled on ice for 10 minutes. Then, pyronin Y (Sigma-Aldrich) was added at a final concentration of $5 \mu \mathrm{M}$, cells were incubated for additional 10 minutes on ice, and finally fixed in $2 \%$ paraformaldehyde until analysis.

HIV-1 Env gp120 and LTR U3 genotype characterizations. The sequences of the V1 to V5 region of HIV-1 Env gp120 of both proviral DNA (isolated from CD8-depleted PBMCs and purified resting $\mathrm{CD}^{+} \mathrm{T}$ lymphocyte) and virionencapsidated RNA (as cell-free virus outgrowth in coculture supernatants) were determined by nested PCR assay. Two different time-point supernatant samples were used for viral RNA isolation. Nucleic acid isolation, cDNA synthesis, and PCR amplification of DNA and CDNA were performed as described previously (44). The viral RNA was reverse-transcribed with the Superscript preamplification system (Invitrogen Corp.) with an antisense external primer R02 (5'-TAGTGCTTCCTGCTGCTCCCAAGAACCC-3'), and the cDNA underwent nested PCR. The outer primer pair for the V1 to V5 region of HIV-1 envelope gp120 was F02 (5'-AGAAAGAGCAGAAGACAGTGGCAATGA-3') and R02 (sequence above), and the inner primer pair was F01 (5'-ACACATGCCTGTGTACCCCACGAC-3') and R01 (5'-GTGCTACACCTAATGGTTCAA- $3^{\prime}$ ). The amplified DNAs were isolated from agarose gels, cloned into the pGEM-T easy vector (Promega Corp.), and transformed into competent DH5 $\alpha$ cells (Invitrogen Corp.). Ten to 15 clones were selected and sequenced with an automated sequencer (Prism model 377, with XL upgrade, PerkinElmer Applied Biosystems) The sequences were analyzed using Lasergene sequence analysis software obtained from DNASTAR Inc. Sequence contaminants were ruled out by comparison of obtained sequences with common laboratory viral isolates. The sequences have been submitted to GenBank (accession numbers AY549051 to AY549086 [patient 1], AY549124 to AY549147 and AY553649 to AY553650 [patient 2], AY576490 to AY576525 [patient 3], and AY549087 to AY5494123 [patient 4]). Perfectly matched DNA-based sequences within each patient grouping were not reiterated in the submission. In addition, the full-length viral genomes of patient 3 were sequenced from PMCSs and resting $\mathrm{CD}^{+} \mathrm{T}$ cell supernatants that were stimulated by PHA/IL-2 and IL-7, as described previously (45).

To investigate the possible LTR sequence divergence of diverse cytokineinduced replication-competent viruses, which could regulate viral transcription, viral RNA samples isolated from paired IL-7 and PHA/IL-2 coculture supernatants were employed and the $3^{\prime}$ LTR region was amplified and sequenced. The outer primer set was U3F1 (5'-CAGTCACACCTCAGGTACC-3') and U3R1 (5'-TGCTAGAGATTTTCCACACTG-3'), and the inner primer pair was U3F2 (5'-AGACCAATGACTTACAAGG-3') and U3R2 (5'-TGAGGGATCTCTAGTTACCAGAGT-3').

Phylogenetic analysis. Sequence electrophoregram data were analyzed using Seqman (DNASTAR Inc.). Multiple alignments were performed with CLUSTALW version 1.8 (46). Intrapatient viral envelope sequences were compared with each other and to the control sequence (HXB2), using Lasergene sequence analysis software obtained from DNASTAR Inc. to exclude any possibility of sample contamination. Dendrograms were created by the neighbor-joining method of Saitou and Nei (47). Bootstrap analysis consisting of 1,000 replicates was performed with the CLUSTALIW program. Bootstrap values of $70 \%$ or higher were considered significant.

Infectivity assays. PHA-stimulated PBMCs from HIV-1-seronegative donors (after depletion of $\mathrm{CD}^{+} \mathrm{T}$ lymphocytes and monocyte/macrophages) were infected by viruses induced by IL-7 or PHA/IL-2, as well as the laboratory viral strain NL4-3, for $4-6$ hours at $37^{\circ} \mathrm{C}$. The input viral concentrations were normalized by HIV-1 p 24 antigen equivalents $\left(5 \mathrm{ng} / \mathrm{ml}\right.$ per $1 \times 10^{6}$ cells as the highest dose). Residual input virus was removed and cells $\left(2 \times 10^{6}\right)$ were then cultured, in triplicate, in $2 \mathrm{ml}$ of RPMI-1640 medium plus $10 \%$ FCS for 14 days. The supernatants were collected for the detection of HIV-1 p24 antigen on days 0, 7, and 14 of culture via ELISA.

Cytokine measurements. To assess whether IL-7-treated, resting $\mathrm{CD} 4^{+} \mathrm{T}$ lymphocytes released secondary cytokine(s) that subsequently acted on $\mathrm{CD}^{+} \mathrm{T}$ lymphocyte activation, we cultured purified resting $\mathrm{CD} 4^{+} \mathrm{T}$ lymphocytes either alone or with IL-7 in parallel for 7 days. The cell purity was greater than $99 \%$. The levels of 42 human cytokines (including ENA-78, GCSF, GM-CSF, GRO, GRO-a, I-309, IL-1 $\alpha$, IL-1 $\beta$, IL-2, IL-3, IL-4, IL-5, IL-6, IL-7, IL-8, IL-10, IL-12, IL-13, IL-15, IFN- $\gamma$, MCP-1, MCP-2, MCP-3, MCSF, MDC, MIG, MIP- $1 \delta$, RANTES, SCF, SDF-1, TARC, TGF- $\beta 1$, TNF- $\alpha$, TNF- $\beta$, EGF, IGF-1, Ang, OSM, Tpo, VEGF, and PDGF B) in culture supernatants were evaluated using the Human Cytokine Array III kit (RayBiotech Inc.), according to the protocol provided by the manufacturer.

HIV-1 LTR transactivation and gene-reporter assays. The effects of IL-7 on transactivation of the HIV-1 LTR were analyzed by means of the 1G5 cell line, a Jurkat $\mathrm{T}$ cell line that is stably transfected with an HIV-1 LTRluciferase construct (NIH AIDS Research and Reference Reagent Program). 1 G5 cells $\left(2 \times 10^{6}\right.$ cells/ml maintained in RPMI-1640 media supplemented with $10 \%$ fetal bovine serum) were treated with various concentrations of IL-7 (10-100 ng/ml). Cells were collected at different time points $(6,24$, and 48 hours after addition of IL-7), lysed in $100 \mu \mathrm{l}$ of reporter lysis buffer (BD Biosciences - Pharmingen), and assayed for luciferase activity by using commercially available reagents (BD Biosciences - Pharmingen) with a FB12 Luminometer (Zylux Corp.). The effects of PHA (10 ng/ml), PMA $(10 \mathrm{ng} / \mathrm{ml})$, and IL-2 $(10 \mathrm{ng} / \mathrm{ml})$ were also analyzed separately in these assays.

Statistical analyses. The significance of differences in the efficiency of viral growth from latently infected cells stimulated by IL-7 and PHA/IL-2 was analyzed using the $\chi^{2}$ test. $P$ values of less than 0.05 were considered to be statistically significant.

\section{Acknowledgments}

The authors wish to thank Anne Malin and Ruth Brower for clinical assistance with patients in this study, Rita M. Victor and Brenda O. Gordon for their excellent secretarial support, Hui Zhang for helpful discussions, and especially the patients who volunteered for these studies. This work was supported in part by US Public Health Services grants AI43289 and NS41864 (to R.J.Pomerantz), and the Center for AIDS research (CFAR) AI45008 at the University of Pennsylvania.

Received for publication June 29, 2004, and accepted in revised form October 26, 2004.

Address correspondence to: Roger Pomerantz or Giuseppe Nunnari, Center for Human Virology and Biodefense, Division of Infectious Diseases and Environmental Medicine, Department of Medicine, Thomas Jefferson University, Jefferson Alumni Hall, 1020 Locust Street, Suite 329, Philadelphia, Pennsylvania 19107, USA. Phone: (215) 503-8575; Fax: (215) 503-2624; E-mail: Roger.J.Pomerantz@jefferson.edu (Roger Pomerantz); Giuseppe. Nunnari@jefferson.edu (Giuseppe Nunnari).

Joseph Kulkosky's present address is: Department of Biology, Chestnut Hill College, Philadelphia, Pennsylvania, USA.
1. Siliciano, J.D., et al. 2003. Long-term follow-up studies confirm the stability of the latent reservoir for

HIV-1 in resting CD4+ T cells. Nat. Med. 9:727-728.

2. Chun, T.W., et al. 1999. Effect of interleukin-2 on the pool of latently infected, resting CD4+ T cells in HIV-1-infected patients receiving highly active anti-retroviral therapy. Nat. Med. 5:651-655.

3. Stellbrink, H.J., et al. 2002. Effects of interleukin-2 plus highly active antiretroviral therapy on HIV-1 replication and proviral DNA (COSMIC trial). AIDS. 26:1479-1487.

4. Kulkosky, J., et al. 2002. Intensification and stim- 
ulation therapy for human immunodeficiency virus type 1 reservoirs in infected persons receiving virally suppressive highly active antiretroviral therapy. J. Infect. Dis. 186:1403-1411.

5. Emery, S., et al. 2000. Pooled analysis of 3 randomized, controlled trials of interleukin-2 therapy inadult human immunodeficiency virus type 1 disease. J. Infect. Dis. 182:428-434.

6. Pandolfi, F., et al. 2000. Low-dose IL-2 reduces lymphocyte apoptosis and increases naive CD4 cells in HIV-1 patients treated with HAART. Clin. Immunol. 94:153-159.

7. Pett, S.L., and Emery, S. 2001. Immunomodulators as adjunctive therapy for HIV-1 infection. J. Clin. Virol. 22:289-295.

8. Tambussi, G., et al. 2001. Efficacy of low-dose intermittent subcutaneous interleukin (IL)-2 in antiviral drug-experienced human immunodeficiency virus-infected persons with detectable virus load: a controlled study of 3 IL-2 regimens with antiviral drug therapy. J. Infect. Dis. 183:1476-1484.

9. Namen, A.E., et al. 1988. B cell precursor growthpromoting activity. Purification and characterization of a growth factor active on lymphocyte precursors. J. Exp. Med. 167:988-1002.

10. Benjamin, D., et al. 1994. Human B cell lines constitutively secrete IL-7 and express IL-7 receptors. J. Immunol. 152:4749-4757.

11. Fernandez, E., et al. 1994. Establishment and characterization of cloned human thymic epithelial cell lines. Analysis of adhesion molecule expression and cytokine production. Blood. 83:3245-3254.

12. Watanabe, M., et al. 1995. Interleukin 7 is produced by human intestinal epithelial cells and regulates the proliferation of intestinal mucosal lymphocytes. J. Clin. Invest. 95:2945-2953.

13. Ryan, D.H., Nuccie, B.L., Ritterman, I., Liesveld, J.L., and Abboud, C.N. 1994. Cytokine regulation of early human lymphopoiesis. J. Immunol. 152:5250-5258.

14. Kroncke, R., Loppnow, H., Flad, H.D., and Gerdes, J. 1996. Human follicular dendritic cells and vascular cells produce interleukin-7: a potential role for interleukin-7 in the germinal center reaction. Eur. J. Immunol. 26:2541-2544.

15. Vella, A.T., Dow, S., Potter, T.A., Kappler, J., and Marrack, P. 1998. Cytokine-induced survival of activated T cells in vitro and in vivo. Proc. Natl. Acad. Sci. U. S. A. 95:3810-3815.

16. Vella, A., Teague, T.K., Ihle, J., Kappler, J., and Marrack, P. 1997. Interleukin 4 (IL-4) or IL-7 prevents the death of resting T cells: STAT6 is probably not required for the effect of IL-4. J. Exp. Med. 186:325-330.

17. Boise, L.H., Minn, A.J., June, C.H., Lindsten, T., and Thompson, C.B. 1995. Growth factors can enhance lymphocyte survival without committing the cell to undergo cell division. Proc. Natl. Acad. Sci. U. S. A. 92:5491-5495.

18. Komschlies, K.L., et al. 1994. Administration of recombinant human IL-7 to mice alters the composition of B-lineage cells and $\mathrm{T}$ cell subsets, enhances
T cell function, and induces regression of established metastases. J. Immunol. 152:5776-5784.

19. Grzegorzewski, K.J., et al. 1995. Mobilization of long-term reconstituting hematopoietic stem cells in mice by recombinant human interleukin 7 . J. Exp. Med. 181:369-374.

20. Carini, C., and Essex, M. 1994. Interleukin 2-independent interleukin 7 activity enhances cytotoxic immune response of HIV-1-infected individuals. AIDS Res. Hum. Retroviruses. 10:121-130.

21. Bui, T., Dykers, T., Hu, S.L., Faltynek, C.R., and Ho, R.J. 1994. Effect of MTP-PE liposomes and interleukin-7 on induction of antibody and cell-mediated immune responses to a recombinant HIV-envelope protein. J. Acquir. Immune Defic. Syndr. 7:799-806.

22. Kaech, S.M., et al. 2003. Selective expression of the interleukin 7 receptor identifies effector CD8 T cells that give rise to long-lived memory cells. Nat. Immunol. 12:1191-1198.

23. Napolitano, L.A., et al. 2001. Increased production of IL-7 accompanies HIV-1-mediated T-cell depletion: implications for T-cell homeostasis. Nat. Med. 7:73-79.

24. Llano, A., et al. 2001. Interleukin-7 in plasma correlates with CD4 T-cell depletion and may be associated with emergence of syncytium-inducing variants in human immunodeficiency virus type 1positive individuals. J. Virol. 21:10319-10325.

25. Smithgall, M.D., Wong, J.G., Critchett, K.E., and Haffar, O.K. 1996. IL-7 up-regulates HIV-1 replication in naturally infected peripheral blood mononuclear cells. J. Immunol. 156:2324-2330.

26. Chene, L., et al. 1999. Thymocyte-thymic epithelial cell interaction leads to high-level replication of human immunodeficiency virus exclusively in mature CD4(+) CD8 $(-)$ CD3 $(+)$ thymocytes: a critical role for tumor necrosis factor and interleukin-7. J. Virol. 73:7533-7542.

27. Moran, P.A., Diegel, M.L., Sias, J.C., Ledbetter, J.A., and Zarling, J.M. 1993. Regulation of HIV production by blood mononuclear cells from HIV-infected donors: I. Lack of correlation between HIV-1 production and T cell activation. AIDS Res. Hum. Retroviruses. 9:455-464.

28. Scripture-Adams, D.D., Brooks, D.G., Korin, Y.D., and Zack, J.A. 2002. Interleukin-7 induces expression of latent human immunodeficiency virus type 1 with minimal effects on T-cell phenotype.J. Virol. 76:13077-13082.

29. Soares, M.V., et al. 1998. IL-7-dependent extrathymic expansion of CD45RA+ T cells enables preservation of a naive repertoire. J. Immunol. 161:5909-5917.

30. Unutmaz, D., KewalRamani, V.N., Marmon, S., and Littman, D.R. 1999. Cytokine signals are sufficient for HIV-1 infection of resting human T lymphocytes. J. Exp. Med. 189:1735-1746.

31. Nugeyre, M.T., et al. 2003. L-7 stimulates T cell renewal without increasing viral replication in simian immunodeficiency virus-infected macaques. J. Immunol. 171:4447-4453.

32. Steffens, C.M., Managlia, E.Z., Landay, A., and AlHarthi, L. 2002. Interleukin-7-treated naive T cells can be productively infected by T-cell-adapted and primary isolates of human immunodeficiency virus 1. Blood. 99:3310-3318.

33. Armitage, R.J., Namen, A.E., Sassenfeld, H.M., and Grabstein, K.H. 1990. Regulation of human T cell proliferation by IL-7. J. Immunol. 144:938-941.

34. Welch, P.A., Namen, A.E., Goodwin, R.G., Armitage, R., and Cooper, M.D. 1989. Human IL-7: a novel T cell growth factor. J. Immunol. 143:3562-3567.

35. Fukui, T., et al. 1997. IL-7 induces proliferation, variable cytokine-producing ability and IL-2 responsiveness in naive $\mathrm{CD} 4+\mathrm{T}$-cells from human cord blood. Immunol. Lett. 59:21-28.

36. Yssel, H., Schneider, P.V., and Lanier, L.L. 1993. Interleukin-7 specifically induces the $\mathrm{B} 7 / \mathrm{BB} 1$ antigen on human cord blood and peripheral blood $\mathrm{T}$ cells and T cell clones. Int. Immunol. 5:753-759.

37. Borvak, J., et al. 1995. Expression of CD25 defines peripheral blood mononuclear cells with productive versus latent HIV infection. J. Immunol. 155:3196-3204.

38. Fry, T.J., et al. 2003. IL-7 therapy dramatically alters peripheral T-cell homeostasis in normal and SIV-infected nonhuman primates. Blood. 101:2294-2299.

39. Brooks, D.G., et al. 2003. Molecular characterization, reactivation and depletion of latent HIV. Immunity. 19:413-423.

40. Ducrey-Rundquist, O., Guyader, M., and Trono, D. 2002. Modalities of interleukin-7 induced human immunodeficiency virus permissiveness in quiescent T lymphocytes. J. Virol. 76:9103-9111.

41. Kulkosky, J., et al. 2003. Genotypic alteration of HAART-persistent HIV-1 reservoirs in vivo. Virology. 314:617-629.

42. Otero, M., et al. 2003. Peripheral blood dendritic cells are not a major reservoir for HIV type 1 in infected individuals on virally suppressive HAART. AIDS Res. Hum. Retroviruses. 19:1097-1103.

43. Toba, K., Winton, E.F., Koike, T., and Shibata, A. 1995. Simultaneous three-color analysis of the surface phenotype and DNA-RNA quantitation using 7-amino-actinomycin D and pyronin Y. J. Immunol. Methods. 182:193-207.

44. Wang, F.X., et al. 2002. Emergence of autologous neutralization-resistant variants from preexisting human immunodeficiency virus (HIV) quasispecies during virus rebound in HIV type 1-infected patients undergoing highly active antiretroviral therapy. J. Infect. Dis. 185:608-617.

45. Casado, G., et al. 2003. Near full-length genome characterization of an HIV type 1 CRF05_DF virus from Spain. AIDS Res. Hum. Retroviruses. 8:719-725.

46. Thompson, J.D, Higgins, D.G., and Gibson, TJ. 1994. CLUSTAL W. improving the sensitivity of progressive multiple sequence alignment through sequence weighting, position-specific gap penalties and weight matrix choice. Nucleic Acids Res. 22:4673-4680.

47. Saitou, N., and Nei, M. 1997. The neighbor-joining method: a new method for reconstructing phylogenetic trees. Mol. Biol. Evol. 4:406-425. 